\title{
An After Life
}

\section{Lt Col (Retd) R J Knight, RAMC \\ Consultant Anaesthetist \\ * clo Aramco, PO Box 9134, Dhahran 31311, Saudi Arabia}

Until the sea-scimming missile (beloved of the tabloid press) streaked into the USS Stark, it had become quite tempting to imagine that the Gulf Region had replaced Frinton-on-Sea as the retirement Mecca for a generation of RAMC Officers.

The author, in less than a year in Saudi Arabia, has met former Corps surgeons, physicians, anaesthetists, paediatricians, an obstetrician, two administrative officers and two former ladies of the QARANC, all working in different hospitals throughout the Kingdom. Other serving and former members of the Corps have come and gone, most often as locums, a few with the intent of prospecting for a new career, most driven by an urgent financial commitment to top up either mortgage or university fees. Of those who take a job in the Gulf, a little over two and a half years appears as the average duration of tenure, seemingly giving the lie to the adage "two years for need, two for greed". One medical officer was repatriated at his own request after less than a week into his job, but others have remained to become Chief of their specialty, and two, both surgeons, to become hospital directors. Very senior former members of the Corps have been appointed $a b$ initio as hospital directors to the larger more prestigious military units.

That some knowledge relating to the Arab world still exists within the Corps is not in question. It is now, however, restricted to a very few who served in Egypt prior to 1952 (and briefly in 1956), in Aden prior to 1967, in Amman during Operation Shoveller in 1968, in Libya before the advent of Colonel Gaddafi in 1968, and in Bahrain before independence in 1971.

The author's exposure to Arabia prior to 1985 was as a member of one of the many Field Surgical Teams supporting the Sultan of Oman's Forces during Operation Storm (the Dhofar Campaign), and to African Islam during a protracted Parachute Brigade Battle Group Exercise in the Sudan. It would be fair comment to observe that a lifetime spent on the North German Plain will prove of little value in helping the newly expatriate medical officer to come to terms with either the climate, political and meteorological, or the culture of the Arabian Peninsula.

How then does the reality of the post oil-boom Arabic world of the late 1980 's relate to that knowledge? Do the blandishments of the recruiting agencies, their wares displayed on whole page adverts in the British Medical Journal and elsewhere resemble the date palm in that they do not always bear fruit? Or does the lengthy parade of digits formed up after the pounds sterling symbol in the advert resemble the sands of the empty quarter during a storm - sufficient to blind the unwary traveller?

Arabia's unbelievable income from the 1973 quadruple increase in crude oil prices reversed the peninsula's former relationship with the West; in the span of a very few months the Gulf region became a land of milk and honey, whilst the industrialised West began to resemble an ever-encroaching desert, as national economies, and Governments, fell in the wake of huge increases in unit costs and massive unemployment, both brought about by the seemingly endless rises in energy costs. The Gulf States of 1986 have emerged from a golden decade into a significantly harsher world of political and fiscal realism.

In addition to changes in the economic climate of the region, any medical officer contemplating a career in the Gulf would be well advised to consider the volatile and sometimes violent political realities to be found there and their far-reaching international repercussions.

Such major political considerations notwithstandin $\overrightarrow{\mathrm{g}}$ what other factors are relevant in the decision-making process before a medical officer finalises a commitmenf to the Gulf? Professional satisfaction, remunerationt leave, living conditions and career prospects are those which spring most readily to mind.

Salaries in Saudi Arabia have, to date, been moke generous than elsewhere in the Gulf Region. The silent explanation for this is that expatriates have found it more difficult to live within the rigidity of Saudi Islam than in the more laissez-faire Emirates or in the more westernised Oman and Bahrain. This apparent generosity on the part of Saudi Arabia has been cut back sharply by up to a third when compared to salaries on offer in 1984.

Then, a retiring Colonel, a Consultant of fifteen or more years standing, could confidently expect to receive (often in cash) a salary in excess of $£ 60,000$ per annum. This was the salary for a Ministry of Health appointment. In addition to this were added education allowance, a thirteenth month's salary and terminal gratuity (often $20 \%$ of a year's salary) after two or sometimes three years. In April 1986, however, the dual appointment of Hospital Director and Senior Surgeon warranted a salary of $£ 42,000$ per annum without any school fees or other fringe benefits as part of the salary package. The Sultanate of Oman is prepared to pay up to $£ 32,000$ per annum for Consultants together with the intangible benefits of access to commercially prepared alcohol and the perhaps dubious privilege of allowing one's wife to drive. These expatriate salaries may be 
compared with that of a serving Brigadier Consultant's pre-tax income of $£ 40,000$, or with that of an established NHS Consultant with Merit Award and private practice. Given such a comparison, salaries in the Gulf Region are no longer intrinsically high, but they retain their attractiveness solely because they are not subject to direct taxation and that residence in the Gulf provides an opportunity for off-shore investment. Some hospitals in Saudi currently deduct "hypothetical income tax" from their expatriate employees, and there is now reason to suppose that the imposition of a form of Income Tax is to be launched in 1988 on all wage earners within the Kingdom. In February 1987 the Saudi Goverment withdrew totally its previously generous pension scheme for expatriates; a twenty year expatriate, having paid $5 \%$ of his annual salary (and his employer $8 \%$ ) to the pension fund, now finds himself without a pension and without any clear idea as to whether or not he will receive his contributions as a "lump sum".

The majority of expatriate medical officers sign an initial annual contract with a hospital management company, most of which are American based. Provision for a review of salary and fringe benefits on completion of the year is normal. Renewals are currently taking place, however, without an increase in either basic salary or benefits. An annual review in one hospital has come to mean that the salary revision occurs after eighteen months with implementation of the award, if any, at some point thereafter. Such unilateral interpretation of what was considered to be a legally binding contract, signed in England, has generated considerable ill-will amongst those expatriates in possession of that contract. Many 'expensive' western doctors are being replaced in hospitals throughout the Kingdom by 'cheaper' Indian, Pakistani and Arab graduates, particularly Palestinians. The non-renewal of his contract was the fate which overtook an ex-Corps Physician recently; he wished to complete a third year in a Government hospital but was rejected in favour of an Indian who accepted less than half the salary paid to the St Thomas's graduate.

Whilst the internationalism of expatriate medicine may at first appear as one of its more attractive facets for some, the retention of the social and professional mores to which they have become accustomed during their years of service is not always easy. The author's professional colleagues range from a Finnish tax exile from Helsinki to a South African Boer evading the racial policies of his homeland. A few isolated pockets of active American medicine remain within the Kingdom. A significant proportion of American doctors practising in Arabia are themselves ex-military and enjoy, on average, a salary twice that of a British expatriate; this together with their remarkably generous pension schemes permits them an extremely high standard of living. Most of these doctors will readily admit their considerable reluctance to tangle with the miasma of malpractice litigation and peer review committees which permeate medicine in the USA and which now $\operatorname{loom}_{3}$ darkly over the Hippocratic ethos of medical practice in the United Kingdom. Nonetheless, American medical $\stackrel{\Omega}{\Omega}$ practice continues to be a major influence in Saudio Arabia and is the yardstick by which all comparisons are made, eg super-specialist teams from the United States $\Rightarrow$ are flown into the Kingdom to demonstrate new technologies and operative methods.

A further example of the Americanization of Saud흠 medical care is seen in the increasingly aggressive $e^{\bar{n}}$ financial and marketing techniques developed by the US hospital management groups, more especially so byes those in the Government sector. To remain competitivethe smaller privately owned hospitals are tending to form consortia in which each member attempts to offer $\vec{\omega}$ a super-specialist area of expertise. As an example of theo "new order", a Consultant Anaesthetist, an EgyptianAmerican, was recently "advised" by the hospitaB accountant to complete the preparation for and? induction of anaesthesia for elective coronary artery $\overrightarrow{+}$ surgery (arterial line, internal jugular line, twoo peripheral lines and a Swan-Ganz pulmonary catheter $\overrightarrow{0}$ to teach a junior anaesthetist and to correct a a hypotension and subsequent dysrythmias) within 95 马 minutes. The management rationale for this "advice"was that, to take more than a quarter of an hour per cas was potentially to deprive the hospital of an additiolig? income of $\$ 100,000$ per month. It is worth commenti澫g that all "real money" calculations in the Gulf $\overline{\text { e }}$ measured against the US dollar.

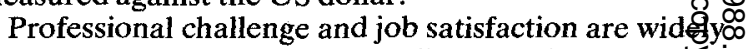
available in Arabia, but both, sadly, are quite capable $\mathbf{f}$ evading the expatriate medical officer. Job satisfaction per se can be reduced by the apparently idiosyncratic attitudes of the patients to their diseases, to theiro immediate treatment, and by their approach to thosexp who are attempting to provide that treatment. In obstetric practice, the absolute refusal of a husband too permit his child to be born by Caesarian section is an everyday occurrence, regardless of the indications for and urgency of operation. In medicine, it is virtually impossible to treat hypertension with beta blockers because of their reputation for causing impotence there are no old men in Arabia. A Saudi father refused operation for his 11 year old son for an obvious acuteo appendicitis, preferring to put his trust in the triba告 medicine man, only to return to the hospital five days later with the boy in septicaemic shock. An adequate explanation for this behaviour is difficult to pin-point given the unending stream of health campaigns organised by the Goverment and the television exposureo of the population to western medicine, both as? information and (more regrettably) as entertainment. Such behaviour may be either a reflection of a credibility. gap between medicine and the Arab perception of "illness", or a cultural phenomenon implicit in then Islamic tenet that all things are the will of Allah.N 
Nonetheless, a therapeutic mishap or surgical misadventure can rapidly precipitate either substantial financial reparations to the patient's family (blood money), a prison sentence, or deportation, or all three for the medical officers involved in the case. Three month's unpaid work, a month in prison and deportation was the sequence of events which overtook a retired Royal Navy Surgeon in the very recent past. Deportation normally takes place after the findings of an "investigation" are made public. Such "investigations" are invariably performed in secret by the religious authorities of the region; impartial medical input to the investigation is rare and takes the form of a review of the case notes by a member of the regional university. The doctors involved in the incident are neither present nor represented and there is no right of appeal against these findings. The infallability of Sharia Law and its prescribed punishments, together with the all-pervasive layers of Government authority, engender a sensation of constant apprehension in many expatriates; amongst medical officers this promotes both defensive medicine and an even more defensive lifestyle.

The epidemiology of the disease patterns of the Arabian Peninsula is an admixture of the familiar (diabetes, hypertension and ischaemic heart disease) and the relatively unfamiliar (schistosomiasis, hydatid disease, extensive brucellosis and a variety of haemoglobinopathies). In obstetric practice, grand multiparity is the norm, and the principal problem in obstetrics is to try to persuade the Saudi patients to accept anti-natal care. Diarrhoeal disease in the first months of life represents a significant cause of infant mortality. For the surgeon, road traffic accidents provide the single most frequent challenge. Gunshot wounds received during feuds are not uncommon in the more remote areas where the Bedouin lifestyle persists. There is little doubt that significant shifts in disease patterns have occurred during the Gulf's "Golden Decade"; one example is in dental caries. Deep waterwells, for generations the sole source of water, were over-rich in fluoride, and produced brown-stained but rock hard teeth. Desalinated sea water is now piped through the Kingdom. As it is devoid of fluoride ion, the teeth of the nation's children are beginning to reflect this deficiency, aided, no doubt, by the ubiquitous cola and candy bars.

Diagnostic, laboratory and therapeutic hardware is invariably culled from the upper realms of European or American technology and most hospitals can only be described as lavishly equipped. Little serious thought would seem to have been given to the necessity of purchasing some of the hi-tech facilities. The author recently visited a 150 bed military hospital replete with a CAT scanner, and two more such instruments were in situ in other hospitals in the town which boasted, at best, a population of 60,000 . Problems in supply and training occasionally limit the effectiveness of some of this equipment however. Biomedical units of measurement are the once familiar milli-equivalents and milligrams percent, a reflection of the failure of the SI units to cross the Atlantic.

Living conditions for medical officers within different hospitals vary considerably. The spectrum viewed by the author whilst visiting former members of the Corps ranged from a two-roomed flat in an asbestos-roofed breeze-block hut (the home of a former Consultant Adviser whose knowledge of entomology enabled him to identify his nocturnal companions) to a threebedroom, house-boy included apartment in the capital city. Recreational facilities within hospitals vary in a similar manner from virtually none to one hospital which, in addition to tennis, squash, olympic pools, a yacht club and weight training rooms, is able to boast three sets of sauna baths.

The international hotel chains quite frequently include sports complexes within their facilities and annual membership fees for these range from $£ 100$ to $£ 250$. Jogging is popular with expatriates of all nationalities; whether this is a manifestation of a wish to remain physically fit or an escape route for inner frustrations is uncertain. Ten kilometre, half marathor and, indeed, marathon road races are held in the coolef? weather. The Saudi Arabs themselves, for historicato reasons, do not have a sporting tradition, although football is increasing steadily in popularity (the $198 \mathrm{~B}$ Mexico World Cup was carried live by most TV stationsD in the Gulf) and cricket is popular in the Emirates.

Segregation of the sexes is a major aspect of Islamic life, more so in Saudi Arabia than in some other Gulp States. The extent to which this doctrine is applied to the expatriate community in different areas of the Kingdorf? occasionally seems haphazard, and is quite capable of overnight change. At one hospital in the restricted military zone close to the Jordanian border, all female employees are kept literally under lock and key to prevent them being seen in public. They are bussed from their accommodation the few tens of metres to the hospital main entrance, but, once inside, they are free to walk, talk and dine with whomsoever they may choose. Muslim/non-Muslim and male/female separation in hospital cafeterias is common. Mixed bathing in hotel pools is prohibited. Even to stay in a hotel, a married woman is required to produce her passport, her husband his work permit, and the requisite Government documentation permitting him to travel within the Kingdom. This paperwork is routinely scrutinised by hotel reception staff to ensure that an adulterous relationship does not exist between the guests. In the case of a Saudi woman, the punishment for such a relationship is to be stoned to death; expatriates may expect jail and deportation. Expatriate women may offend the religious authorities by not covering their arms or ankles when appearing in public. To avoid this, many women wear the all-enveloping formless black dress, or habiyah, but even this deference to Islam may 
give rise to dissatisfaction if the garment is deemed to be worn incorrectly. Forty-seven English and Irish nurses and radiographers were deported at a stroke from a hospital in Riyadh in the autumn of 1986.

A career structure in any way similar to the one they have left behind quite simply does not exist for expatriate medical officers in Arabia. Irrespective of their previous rank, experience and status, all expatriate doctors (indeed all expatriates) are ultimately "hired hands" and are regarded and treated as such by all levels of the indigenous population. A specialty Chief or hospital Director has ultimately to answer to a National of the country, who may or may not be western orientated and who may or may not have achieved his position solely by dint of professional qualifications and talent.

As in so many other areas, hours and indeed days worked per week by hospitals in Saudi vary from one region to another; most Government hospitals are open from $7 \mathrm{am}$ to $4 \mathrm{pm}$ daily except on Friday which is the Holy Day. A more fortunate minority work from 7 am to $3.30 \mathrm{pm}$ five days per week. Three days leave per Gregorian month appears to be the national norm for married accompanied medical officers in Saudi. Those on single status are granted four days per month. Nurses accumulate leave at the lower rate of $2 \frac{1}{4}$ days per month ( 28 days per year). The Sultanate of Oman, however, offers 60 days leave per annum. Paid 'Travel Days' may or may not be granted by the employer, and a predetermined number of months may have to be worked before an employee is permitted to take leave. For example, nurses are currently expected to complete a year in the Kingdom before taking leave. The newly opened road bridge to Bahrain provides a weekend respite for many. In Bahrain, perhaps as a British legacy, alcohol is available in hotels, women do not normally veil and are permitted to drive, and the shops do not close five times a day for prayer.

Communication between expatriate medical staff and patients is not always easy, a crash course in medical Arabic notwithstanding. The majority of Arab men speak some English but this is not the case with womenfolk, although this is slowly changing because of TV "soap operas" ("Dallas" with subtitles) and English speaking domestic servants. Radio and television newscasts are carefully structured in Saudi Arabia, but it is quite possible to listen to the BBC World Service as a source of international news. All foreign television programmes shown on TV in Saudi are rigidly examined prior to a public airing to ensure that the content complies with the Islamic precepts of family life and propriety. Censorship of newspapers and magazines is routine and crude; a large black fibre tip obliterates any article or picture considered inappropriate and frequently whole pages are torn away. Video tapes are screened by the customs authorities at the point of entry and this inspection process can generate considerable delays at airports. Communication with the UK by means of a direct dial satellite link is simple and costs $£ 2.00$ per minute from Arabia and $£ 1.50$ per minute from UK. Postal services are essentially good, but proneD to the vagaries of the region. Air travel between Europe and Arabia suffers from a relative over-capacity of aircraft seats, and significant discounts (in excess of $50 \%$ of IATA advertised prices) are available. The Bahrain: Causeway offers access to airlines which do not have landing rights in Saudi Arabia, such as Qantas.

Consumer durables and luxury items aboun throughout the region and at present there is no direct? taxation on these items. Food, flowers and fashion good $\mathbb{8}$ are all expensive, but petrol costs $30 \mathrm{p}$ per gallon Japanese cars are less costly than they are in the UK, buf? are rising in price as the yen continues to rise against the dollar. Korean automobiles are now increasingly seen in the Gulf, as are Korean electronic products; both undercut the yen. The road system in Arabia is excellen but the standard of driving is universally appalling Many expatriates simply refuse to drive, thereby? eliminating the chance of visiting jail as either $\not{W}$ participant in or a witness to a high speed motor vehicle accident or tyre blow-out.

Rumours of impending social and political charfise abound in Saudi; one such rumour suggests that SaupdP women, now better educated than ever before, may beencouraged to play a larger role in National life ands reduce the country's dependance on expatriate labsie in some service areas; nursing would be an example.

Despite this, the British Medical Journal and Lanet still advertise on behalf of hospitals in the Gulf for mêsto medical specialists and for nurses - particuliaf 190 midwives. Since most developed countries in the West have made it far from easy for foreign medical graduates to gain postgraduate clinical experience within thein hospitals, it may be assumed that the Gulf will continue to have a need for expatriate medical expertise ap consultant levels for perhaps another decade, or unti? such time as their own graduates build a medical systen? comparable with or better than that of the West Training within the Eastern bloc, which is common fo many countries in Africa and Asia, is not particularly. acceptable at the moment to the absolute monarchies o프. the region. The majority of pre-clinical and clinica teachers in the medical colleges of Saudi Arabia are expatriates, frequently African, who are enjoying financially rewarding sabbatical of one or two years in the region. English is still the language of medicaf education, but this will change to Arabic when sufficien indigenous academics are in post. At present, expatriate academics who are annually graded as less than eitheß outstanding or excellent have their contracts terminated. To be graded good, is bad. The teaching staff do not grade students.

There can be little doubt that many clinicians in the Royal Army Medical Corps who have practise medicine over a wider geographical area than many doctors, are well qualified to assist the professionail 
aspirations of newly qualitied Gulf graduates. This highly personalised view of Arabia has attempted to cast some light on several less well known aspects of life and medical practice in the region. Any medical officer who is considering a delay in taking his place in God's waiting room at Frinton-on-Sea should remember that, just as a droplet of spilt crude oil glisters in the Middle Eastern sun, all that glisters is not gold.

\section{THE SYNTEX AWARD}

In 1982 Syntex Pharmaceuticals instituted an award for projects submitted by RAMC General Practice Vocational Trainers. The Annual Prize is $£ 100$ and is administered by the RAMC Prize Fund through a nominated Syntex Award Committee.

The 1986 Syntex Award was won by Captain R G W Anderson with a paper entitled "Uptake of Measles Vaccine in an Army Group Practice". He is seen here being presented with cheque and bound copy of his paper by DGAMS, Lt Gen Sir Cameron Moffat. Mr Barry Turner, the Syntex representative, is also in attendance.

Captains T D Manners and P E Sharples were runners-up in the competition and received book-token co prizes from Syntex for a paper on the audit of a Paediatric Survcillance Programme in an Army Group? Practice.

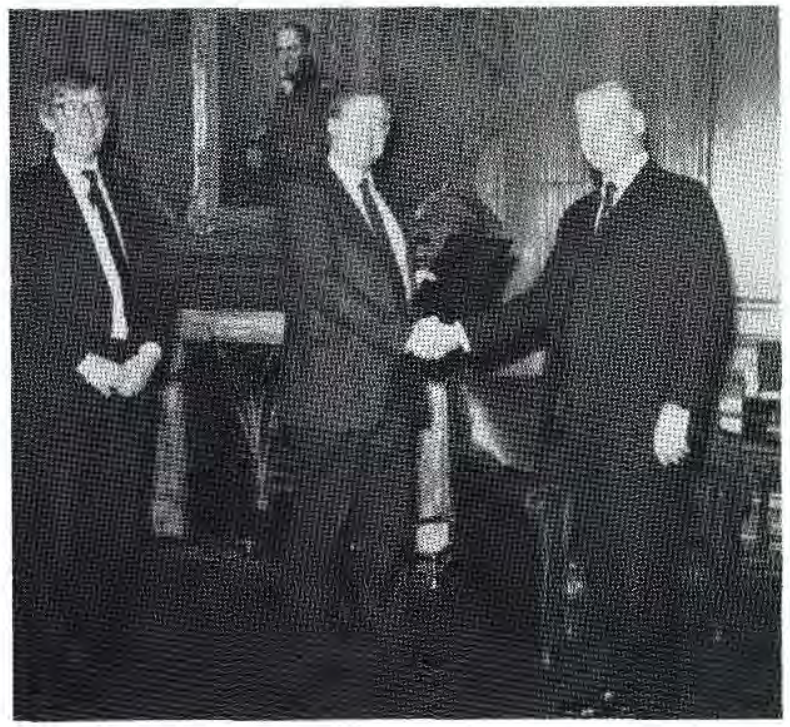

